\title{
Penerapan Metode Discovery Learning untuk Meningkatkan Keterampilan Menulis Puisi
}

\author{
Haifa Amalia Sholiha $\left({ }^{1}\right)$, Nur Amalia $\left({ }^{2}\right)$ \\ Program Studi Pendidikan Bahasa dan Sastra Indonesia, Universitas Muhammadiyah Prof Dr. Hamka $\left({ }^{1}\right)$ \\ Program Studi Pendidikan Bahasa dan Sastra Indonesia, Universitas Muhammadiyah Prof Dr. Hamka $\left({ }^{2}\right)$ \\ Email: haifaamalias@gmail.com $\left({ }^{1}\right)$, nur21amalia@gmail.com $\left({ }^{2}\right)$
}

Riwayat artikel: submit: 17 Juli 2021; revisi: 23 September 2021, diterima: 30 September 2021

\begin{abstract}
ABSTRAK
Tujuan dari penelitian ini yaitu mengetahui bagaimana penerapan metode discovery learning keterampilan menulis puisi kelas X. Pembelajaran adalah salah satu cara pendidikan dalam upayanya untuk mengembangkan potensi yang ada pada diri peserta didik. Potensi tersebut ditingkatkan menjadi kepandaian yang berkompeten, baik dari bidang sikap, pengetahuan, maupun keterampilan. Metode discovery learning merupakan salah satu metode pembelajaran yang dapat meningkatkan kemampuan menulis. Menulis puisi adalah salah satu kreativitas di bidang sastra yang mencerminkan hasil pengalaman, pengetahuan, dan perasaan penyairnya yang dibentuk menjadi sebuah puisi. Pembelajaran tentang menulis puisi terdapat pada materi siswa kelas X Kurikulum 2013 pada Kompetensi Dasar 4.17 Menulis puisi dengan memerhatikan unsur pembangunnya. Oleh karena itu pada artikel ini penulis akan memaparkan bagaimana penerapan metode discovery learning pada keterampilan menulis puisi peserta didik.

Kata kunci: Peserta didik, Keterampilan menulis, Metode Discovery Learning

\section{ABSTRACT}

The purpose of this study is to find out how to apply the discovery learning method to poetry writing skills in class $X$. Learning is one way of education in its efforts to develop the potential that exists in students. This potential is increased into competent intelligence, both in terms of attitudes, knowledge, and skills. The discovery learning method is one of the learning methods that can improve writing skills. Writing poetry is one of the creativity in the field of literature that reflects the results of the experience, knowledge, and feelings of the poet which is formed into a poem. Learning about writing poetry is found in the material for class X 2013 Curriculum students at Basic Competence 4.17 Writing poetry by paying attention to the building blocks. Therefore, in this article the author will explain how the application of the discovery learning method to students' poetry writing skills.

Keywords: Students, Writing Skills, Discovery Learning Method
\end{abstract}

\section{Copyright (C) 2021 The Author(s)}

This is an open access article under the CC BY-SA license. 
Sholiha, H.A. (2021). Penerapan Metode Discovery Learning Untuk Meningkatkan Keterampilan Menulis Puisi. Edudikara: Jurnal Pendidikan dan Pembelajaran, 6(3), 158-162.

\section{PENDAHULUAN}

Pembelajaran adalah salah satu cara pendidikan dalam upayanya untuk mengembangkan potensi yang ada pada diri peserta didik. Potensi tersebut ditingkatkan menjadi kepandaian yang berkompeten, baik dari bidang sikap, pengetahuan, maupun keterampilan. Dalam lingkup pendidikan sekolah, Bahasa Indonesia adalah mata pelajaran utama. Menurut Tarigan (dalam Purba, 2020) ada empat jenis keterampilan dalam pembelajaran Bahasa Indonesia yaitu menyimak, berbicara, membaca, dan menulis. Kegiatan menulis adalah kegiatan yang tidak dapat dipisahkan dalam pembelajaran peserta didik karena dengan menulis peserta didik diajarkan untuk mencari serta menguasai informasi yang berhubungan dengan topik yang akan ditulis.

Metode discovery learning merupakan salah satu metode pembelajaran yang dapat meningkatkan kemampuan menulis. Human (dalam Sitohang et al., 2019) mengatakan bahwa metode discovery learning adalah metode pembelajaran yang memiliki cara belajar aktif yang mengajarkan peserta didik untuk mendapatkan dan menganalisis informasi secara mandiri sehingga hasil yang didapatkan tahan lama dalam ingatan mereka.

Menulis puisi adalah salah satu kreativitas di bidang sastra yang mencerminkan hasil pengalaman, pengetahuan, dan perasaan penyairnya yang dibentuk menjadi sebuah puisi. Pembelajaran tentang menulis puisi terdapat pada materi siswa kelas X Kurikulum 2013 pada Kompetensi Dasar 4.17 Menulis puisi dengan memerhatikan unsur pembangunnya. Oleh karena itu pada artikel ini penulis akan memaparkan bagaimana penerapan metode discovery learning pada keterampilan menulis puisi peserta didik.

\section{ANALISIS}

\section{Kegiatan Menulis}

Dalam lingkup pendidikan sekolah, Bahasa Indonesia adalah mata pelajaran utama. Mata pelajaran Bahasa Indonesia terdapat pada tingkat pendidikan sekolah dasar hingga universitas. Hal tersebut membuktikan bahwa Bahasa Indonesia penting untuk dipelajari oleh peserta didik agar dapat berkomunikasi menggunakan Bahasa Indonesia dengan baik dan benar. Menurut Tarigan (dalam Purba, 2020) ada empat jenis keterampilan dalam pembelajaran Bahasa Indonesia yaitu menyimak, berbicara, membaca, dan menulis.

Menulis adalah salah satu keterampilan berbahasa yang berfungsi untuk berkomunikasi tidak langsung atau langsung dengan menggunakan tulisan (Citaningsih, 2020). Akhadhiah (dalam Dewi et al., 2018) mempunyai padangan bahwa menulis adalah sebuah cara untuk menguangkan gagasan ke dalam bahasa tulis yang memerlukan berbagai tahapan dalam mewujudkannya yang merupakan satu sistem yang utuh. Tahapan-tahapan tersebut adalah tahap memperoleh ide, mengolah ide, hingga memproduksi ide.

Kegiatan menulis adalah kegiatan yang tidak dapat dipisahkan dalam pembelajaran peserta didik. Dengan menulis peserta didik diajarkan untuk mencari serta menguasai informasi yang berhubungan dengan topik yang akan ditulis. Kegiatan menulis dalam pembelajaran bahasa menghadapkan peserta didik pada dunia sebenarnya yang ada di lingkungan sekitar mereka. Peserta didik harus dilatih untuk berhubungan dengan lingkungan sekitar. Mereka harus diberi kesempatan untuk berbaur dengan kehidupan yang sebenarnya dengan bekal pengetahuan yang telah mereka miliki. Dengan begitu mereka mampu berpikir secara konstruktif dan kreatif. Dengan begitu pula peserta didik diharapkan menemukan ide yang akan ia tulis dari lingkungan sekitar dan mengembangkan ide tersebut dengan kreativitas sendiri (Rochmawati \& Ahnaf, 2021). 
Sholiha, H.A. (2021). Penerapan Metode Discovery Learning Untuk Meningkatkan Keterampilan Menulis Puisi. Edudikara: Jurnal Pendidikan dan Pembelajaran, 6(3), 158-162.

\section{Keterampilan Menulis Puisi}

(Ismayani et al., 2018) berpendapat bahwa banyak penulis yang menyatakan keterampilan menulis adalah salah satu kegiatan pembelajaran yang sukar dan tidak banyak peminatnya. Hal ini disebabkan oleh beberapa faktor baik dari peserta didik maupun guru. Selain itu (U. K. Dewi \& Silva, 2018) juga berpendapat bahwa banyak peserta didik mengalami kesulitan menulis dikarenaakan sulitnya menemukan ide dan mengembangkan tulisan sehingga akhirnya mereka berhenti menulis. Namun hal tersebut tidak menutup kemungkinan bahwa keterampilan menulis sangat diperlukan karena pada pembelajaran di sekolah terdapat mata pelajaran yang menuntut peserta didik mampu menulis. Salah satu pembelajaran keterampilan menulis yang ada di kurikulum 2013 adalah pada Kompetensi Dasar 4.17 Menulis puisi dengan memerhatikan unsur pembangunnya.

Menulis puisi adalah salah satu kreativitas di bidang sastra yang mencerminkan hasil pengalaman, pengetahuan, dan perasaan penyairnya yang dibentuk menjadi sebuah puisi. Kegiatan menulis puisi juga bisa disebut sebagai rangkaian kegiatan dalam rangka menuangkan ide yang bersifat imajinatif ke dalam bentuk tulisan (Sigit Vebrianto Susilo et al., 2020). Dapat disimpulkan bahwa keterampilan menulis puisi adalah keterampilan dalam mencurahkan ide, wawasan, dan perasaan kepada pihak lain melalui bahasa tulis.

\section{Metode Discovery Learning}

Dewi (dalam Juliyanti \& Suryani, 2018) berpendapat bahwa discovery learning adalah metode pembelajaran yang berfokus pada pengalaman langsung di lapangan dan tidak mengandalkan teori-teori yang ada di dalam buku teks pelajaran. Selanjutnya Dahar (dalam Pradana et al., 2015) menyatakan bahwa metode discovery learning adalah proses pembelajaran di mana peserta didik tidak disajikan dalam bentuk final, tetapi diharapkan mengorganisasikan secara mandiri. Discovery learning lebih fokus kepada menemukan konsep yang belum diketahui sebelumnya. Dengan begitu dapat disimpulkan bahwa metode discovery learning adalah metode pembelajaran yang dapat membuat siswa berkembang cepat sesuai dengan kecepatan mereka sendiri dan mengarahkan pembelajaran sendiri dengan melibatkan akal dan motivasinya secara mandiri.

Dalam buku panduan implementasi kurikulum 2013 disebutkan langkah-langkah yang dapat diterapkan dalam metode pembelajaran discovery learning sebagai berikut: 1) tahap stimulation (pemberian rangsangan) yaitu menciptakan kondisi peserta didik untuk mengajukan pertanyaan agar peserta didik lebih aktif. 2) tahap problem statement (identifikasi masalah) yaitu kondisi dimana peserta didik diberi kesempatan untuk menyampaikan jawabannya. 3) tahap data collection (pengumpulan data), yaitu peserta didik mencari informasi/bukti untuk mendukung jawabannya. 4) tahap data processing (pengolahan data), yaitu peserta didik mengolah data dengan cara berdiskusi dengan kelompok. 5) tahap verification (pembuktian) yaitu peserta didik mempresentasikan informasi yang telah mereka dapat. 6) tahap generalization (menarik kesimpulan) yaitu peserta didik bersama guru menarik kesimpulan atas informasi yang telah mereka temukan (Rochmawati \& Ahnaf, 2021).

\section{Penerapan Metode Discovery Learning pada Materi Ajar Menulis Puisi Kelas X}

Penerapan metode discovery learning dalam pembelajaran menulis puisi bisa dilakukan dengan cara siswa belajar dengan aktif, berfokus pada proses pembelajaran, mencari pengetahuan secara mandiri, mengarahkan secara mandiri dan cepat tanggap. Langkahlangkah penerapan tersebut adalah sebagai berikut: 
Sholiha, H.A. (2021). Penerapan Metode Discovery Learning Untuk Meningkatkan Keterampilan Menulis Puisi. Edudikara: Jurnal Pendidikan dan Pembelajaran, 6(3), 158-162.

\begin{tabular}{|c|c|c|}
\hline No. & Fase & Kegiatan \\
\hline 1. & $\begin{array}{l}\text { Pemberian } \\
\text { rangsangan }\end{array}$ & $\begin{array}{l}\text { Guru mengajukan pertanyaan terkait materi menulis puisi dengan } \\
\text { memerhatikan unsur pembangunnya. Contoh pertanyaannya bisa } \\
\text { terkait masalah apa yang ada di lingkungan sekitar/berita/media } \\
\text { sosial peserta didik akhir-akhir ini. }\end{array}$ \\
\hline 2. & $\begin{array}{l}\text { Identifikasi } \\
\text { masalah }\end{array}$ & $\begin{array}{l}\text { Peserta didik diberi kesempatan untuk menyampaikan pedapatnya } \\
\text { terkait pertanyaan guru. }\end{array}$ \\
\hline 3. & $\begin{array}{l}\text { Pengumpulan } \\
\text { data }\end{array}$ & $\begin{array}{l}\text { Peserta didik diberi kesempatan untuk mencari dan mengumpulkan } \\
\text { informasi relevan untuk membuktikan apakah jawaban mereka sudah } \\
\text { tepat/belum menggunakan sumber daring. }\end{array}$ \\
\hline 4. & $\begin{array}{l}\text { Pengolahan } \\
\text { data }\end{array}$ & $\begin{array}{l}\text { Peserta didik secara berkelompok mengolah informasi yang } \\
\text { didapatkan menjadi tema untuk menulis puisi dengan } \\
\text { memperhatikan unsur pembangunnya. }\end{array}$ \\
\hline 5. & Pembuktian & $\begin{array}{l}\text { Peserta didik mempresentasikan hasil pengolahan informasi } \\
\text { kelompoknya di depan kelas yaitu dengan membacakan puisi } \\
\text { buatannya. }\end{array}$ \\
\hline 6. & $\begin{array}{l}\text { Menarik } \\
\text { kesimpulan }\end{array}$ & $\begin{array}{l}\text { Peserta didik menarik kesimpulan dari puisi yang sudah dibacakan } \\
\text { oleh temannya. Apakah sudah sesuai dengan materi yang } \\
\text { dibahas/belum. }\end{array}$ \\
\hline
\end{tabular}

\section{SIMPULAN DAN SARAN}

Keterampilan menulis puisi adalah keterampilan dalam mencurahkan ide, wawasan, dan perasaan kepada pihak lain melalui bahasa tulis. Salah satunya model yang tepat dalam pembelajaran menulis puisi adalah model discovery learning. Metode discovery learning adalah metode pembelajaran yang dapat membuat siswa berkembang cepat sesuai dengan kecepatan mereka sendiri dan mengarahkan pembelajaran sendiri dengan melibatkan akal dan motivasinya secara mandiri. Penerapan metode discovery learning dalam pembelajaran menulis puisi bisa dilakukan dengan cara siswa belajar dengan aktif, berfokus pada proses pembelajaran, mencari pengetahuan secara mandiri, mengarahkan secara mandiri dan cepat tanggap.

\section{REFERENSI}

Citaningsih. (2020). Upaya Meningkatkan Efektifitas Pembelajaran Menulis Teks Deskripsi Melalui Metode Discovery Learning pada Siswa. Journal for Lesson and Learning Studies, 3(1), 66-79. https://doi.org/http://dx.doi.org/10.23887/jlls.v3i1.24268.g14705

Dewi, P. C., Hudiyono, Y., \& Mulawarman, W. G. (2018). Pengembangan Bahan Ajar Menulis Teks Prosedur Kompleks Dengan Model Pembelajaran Discovery Learning Menggunakan Media Audio Visual (Video) Di Kelas Xi Sma Negeri 1 Samarinda. DIGLOSIA : Jurnal Kajian Bahasa, Sastra, Dan Pengajarannya, 1(2), 101-114. https://doi.org/10.30872/diglosia.v1i2.pp101-112

Dewi, U. K., \& Silva, P. S. (2018). Penerapan Metode Discovery Learning pada Pembelajaran Menulis Teks Eksposisi. Parole (Jurnal Pendidikan Bahasa Dan Sastra Indonesia), 1(6), 1021-1028. https://journal.ikipsiliwangi.ac.id/index.php/parole/article/view/1733/pdf

Ismayani, M., Romdon, S., \& Triyani, N. (2018). Penerapan Metode Discovery Learning pada Pembelajaran Menulis Teks Anekdot. Parole (Jurnal Pendidikan Bahasa Dan Sastra Indonesia), 1(5), 713-720. https://doi.org/http://dx.doi.org/10.22460/p.v1i5p\%25p.978

Juliyanti, R., \& Suryani, L. (2018). Pembelajaran Menulis Teks Deskripsi dengan Menggunakan Metode Discovery Learning. Parole (Jurnal Pendidikan Bahasa Dan Sastra Indonesia), 1(6), 977-988. https://doi.org/http://dx.doi.org/10.22460/p.v1i6p977-988.1798

Pradana, P. G. A., Artawan, G., \& Darmayanti, I. A. M. (2015). Pembelajaran Menulis Teks Prosedur dengan Metode Discovery Learning di Kelas X MIA 2 SMA Negeri 1 Blahbatuh. E-Journal Jurusan 
Sholiha, H.A. (2021). Penerapan Metode Discovery Learning Untuk Meningkatkan Keterampilan Menulis Puisi. Edudikara: Jurnal Pendidikan dan Pembelajaran, 6(3), 158-162.

Pendidikan Bahasa Dan Sastra Indonesia, Undiksha, 3(1), 341-353. https://doi.org/http://dx.doi.org/10.23887/jjpbs.v3i1.4840

Purba, E. R. (2020). Penerapan Model Pembelajaran Discovery Learning untuk Meningkatkan Kompetensi Menulis Puisi. Jurnal Inovasi Pembelajaran Karakter (JIPK), 5(3), 1-12. http://irpp.com/index.php/jipk/article/view/1190

Rochmawati, F., \& Ahnaf, F. H. (2021). Upaya Meningkatan Kemampuan Menulis Puisi Siswa Kelas VII dengan Model Discovery Learning di SMP Negeri 1 Winongan. Ainara Journal (Jurnal Penelitian Dan PKM Bidang Ilmu Pendidikan), 2(2), 66-71. http://journal.ainarapress.org/index.php/ainj/article/view/28/27

Sigit Vebrianto Susilo, Devi Afriyuni Yonanda, \& Rieta Pratiwi. (2020). Pengaruh Media Big Book terhadap Keterampilan Menulis Puisi Siswa Sekolah Dasar. Jurnal Tunas Bangsa, 7(1), 87-97. https://doi.org/10.46244/tunasbangsa.v7i1.978

Sitohang, Y., Syahfitri, D., \& Siburian, P. (2019). Upaya Meningkatkan Keterampilan Menulis Teks Deskripsi Menggunakan Model Pembelajaran Discovery Learning pada Siswa Kelas VII-C SMPNEGERI 3 Pancur Batu Tahun Pelajaran 2018/2019. Jurnal Darma Agung, 27(2), 942-948. https://doi.org/10.46930/ojsuda.v27i2.266 